\title{
Mark R. Brinker (ed.): Orthopaedic trauma
}

\section{2nd Edition, Wolters Kluwer, Lippincott Williams \& Wilkins, Hardcover, 179.99 US\$, ISBN 13: 978-1-58255-783-0}

\author{
Pierre Kehr ${ }^{1}$
}

Received: 15 March 2016/Accepted: 25 April 2016/Published online: 22 June 2016

(C) Springer-Verlag France 2016

It is about a book published for the preparation of the examinations of orthopaedic surgery and the certificates of requalifications in the USA.

Nevertheless, this book will interest the least young people and by its wide dimensions didactic and the many illustrations.

The many photographs, the drawings and the cuts anatomical make it possible to visualize well and understand described pathology and its treatment. At the end of the chapter, one finds a bibliography whose classification is interesting and very easy to use: it is divided into traditional articles, recent articles and articles of clinical review.

The first part treats general principles of traumatology, fractures and deformations, and biomechanics.
The second part of adult traumatology (upper limb and lower, spine and pelvis).

The third part of paediatric traumatology and the general principles of treatment of the lesions of the upper and lower limbs, the pelvis and the spine.

It is here the second edition which at summer enriched by the novel methods and whose reading is easy even if a particular fracture is sought.

\section{Compliance with ethical standards}

Conflict of interest None.

Pierre Kehr

pierre.kehr@gmail.com

1 Strasbourg, France 